\title{
OPTIMISATION AND CONTROL OF VEHICLE SUSPENSION USING LINEAR QUADRATIC GAUSSIAN CONTROL
}

\author{
LIKAJ Rame ${ }^{1}$, SHALA Ahmet ${ }^{1 *}$ \\ ${ }^{1}$ Faculty of Mechanical Engineering, University of Prishtina, Bregu i Diellit, p.n. 10000 Prishtina, Kosovo \\ * Corresponding author e-mail: ahmet.shala@uni-pr.edu
}

\begin{abstract}
The paper deals with the optimal design and analysis of quarter car vehicle suspension system based on the theory of linear optimal control because Linear Quadratic Gaussian (LQG) offers the possibility to emphasize quantifiable issues like ride comfort or road holding very easily by altering the weighting factor of a quadratic criterion. The theory used assumes that the plant (vehicle model + road unevenness model) is excited by white noise with Gaussian distribution. The term quadratic is related to a quadratic goal function. The goal function is chosen to provide the possibility to emphasize three main objectives of vehicle suspensions; ride comfort, suspension travel and road holding. Minimization of this quadratic goal function results in a law of feedback control. For optimal designs are used the optimal parameters which have been derived by comparison of two optimisation algorithms: Sequential Quadratic Program (SQP) and Genetic Algorithms (GA's), for a five chosen design parameters. LQG control is considered to control active suspension for the optimal parameters derived by GA's, while the main focus is to minimise the vertical vehicle body acceleration.
\end{abstract}

KEYWORDS: Optimisation, Goal Function, optimal control, GA, LQG.

\section{Dynamical model of quarter car vehicle model}

The model of the quarter-car active suspension system used in this paper with two degree of freedom is shown in Fig. 1. The model represents a single wheel of a car in which the wheel is connected to the quarter portion of the car body through a hydro pneumatic suspension. The dynamics of quarter car model in Fig. 1 are described by:

$$
\begin{aligned}
& m_{a} \ddot{z}_{a}-u-c_{v}\left(z_{k}-z_{a}\right)+c_{p}\left(z_{a}-z_{r}\right)=0 \\
& m_{k} \ddot{z}_{k}+u+c_{v}\left(z_{k}-z_{a}\right)=0
\end{aligned}
$$

For quarter car vehicle model expresses in state space form, state variables are chosen as follows:

$$
\begin{aligned}
& z_{a}=x_{1} \\
& \frac{d z_{a}}{d t}=\dot{x}_{1}=x_{3} \\
& z_{k}=x_{2} \\
& \frac{d z_{k}}{d t}=\dot{x}_{2}=x_{4} \\
& \dot{x}_{3}=\frac{u}{m_{a}}+\frac{c_{v}}{m_{a}} z_{k}-\frac{c_{v}}{m_{a}} z_{a}-\frac{c_{p}}{m_{a}} z_{a}+\frac{c_{p}}{m_{a}} z_{r}=\frac{u}{m_{a}}+\frac{c_{v}}{m_{a}} x_{2}-\frac{c_{v}+c_{p}}{m_{a}} x_{1}+\frac{c_{p}}{m_{a}} z_{r}
\end{aligned}
$$




$$
\dot{x}_{4}=-\frac{u}{m_{k}}-\frac{c_{v}}{m_{k}} z_{k}+\frac{c_{v}}{m_{k}} z_{a}=-\frac{u}{m_{k}}-\frac{c_{v}}{m_{k}} x_{2}+\frac{c_{v}}{m_{k}} x_{1}
$$

State space of quarter car model in matrix form are expressed:

$$
\underline{\dot{x}}=\mathrm{A} \cdot \underline{x}+\mathrm{B} \cdot u+\mathrm{G} \cdot z_{r}
$$

where $\underline{x}^{T}=\left[\begin{array}{llll}z_{a} & z_{k} & \dot{z}_{a} & \dot{z}_{k}\end{array}\right]$

$\underline{x}-$ state vector.

Matrix $\boldsymbol{A}$ is state matrix, vector $\boldsymbol{B}$ is input vector for actuator force $u$ and vector $\boldsymbol{G}$ is input from the road disturbance $z_{r}$.

$$
\mathrm{A}=\left[\begin{array}{cccc}
0 & 0 & 1 & 0 \\
0 & 0 & 0 & 1 \\
\frac{-c_{v}-c_{p}}{m_{a}} & \frac{c_{v}}{m_{a}} & 0 & 0 \\
\frac{c_{v}}{m_{k}} & \frac{-c_{v}}{m_{k}} & 0 & 0
\end{array}\right] \quad \mathrm{B}=\left[\begin{array}{c}
0 \\
0 \\
\frac{1}{m_{a}} \\
\frac{-1}{m_{k}}
\end{array}\right] \quad \mathrm{G}=\left[\begin{array}{c}
0 \\
0 \\
\frac{c_{p}}{m_{a}} \\
0
\end{array}\right]
$$

The model parameters and their respective units are summarized in Table 1.

Table 1. Quarter car vehicle model parameters

\begin{tabular}{|l|l|l|}
\hline Symbol & Description & Value \\
\hline$m_{\mathrm{k}}$ & Body mass & $200 \mathrm{~kg}$ \\
\hline $\mathrm{m}_{\mathrm{a}}$ & Wheel mass & $33 \mathrm{~kg}$ \\
\hline$c_{\mathrm{v}}$ & Spring contsnt & $9000 \mathrm{~N} / \mathrm{m}$ \\
\hline $\mathrm{c}_{\mathrm{p}}$ & Spring constant & $200000 \mathrm{~N} / \mathrm{m}$ \\
\hline$k_{v}$ & Damping ratio & $1600 \mathrm{Ns} / \mathrm{m}$ \\
\hline
\end{tabular}

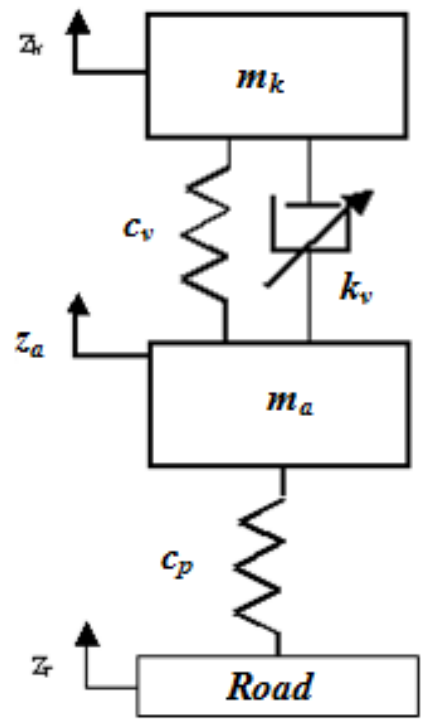

Fig. 1 Quarter car suspension model of 2 DOF 


\section{Design Optimisation}

In this section, the sprung mass vertical acceleration is minimized, while the design constraints on the suspension working space and dynamic tire load should be satisfied. To implement the design optimization, the two optimization algorithms, i.e, SQP and GA, will be applied, respectively.

\section{Optimization based on SQP algorithm and GA}

The SQP algorithm is a non-linear programming technique that is used for the purpose of minimizing a smooth non-linear function subjected to a set of constraints with upper and lower bounds. The objective function and the constraint functions are assumed to be at least twice continuously differentiable. This algorithm is a gradient-based search method [3],[4]. This algorithm is well-suited for constrained design optimizations. The reliability for finding the optimum decreases with the increase of number of design variables when using SQP method. In contrast, whether the number of design variables increase the GA can still reliably find the optimum. This can be explained by the fact that GA works on a population of variables in parallel, not on a unique point. GAs are a global search methods that are based on the Darwin's principle of natural selection and genetic modification and have higher reliability for the global optimum with minimum number of computational operations.

The RMS of the acceleration of a sprung mass ${ }^{\sigma_{z_{k}}}$ is frequently used to evaluate the riding quality of a vehicle. A rider's comfort improves as the acceleration decreases. Ride comfort is chosen to be the design criterion. The suspension working space and dynamic tire load ${ }^{\sigma_{f d}}$ are selected as the design constraints. The design variables are $\mathrm{m}_{1}, \mathrm{~m}_{2}, \mathrm{k}_{1}, \mathrm{k}_{2}$ and $\mathrm{c}_{\mathrm{s}}$, respectively.

Thus, the design optimization problem can be obtained by minimisation of sprung mass acceleration [2], [3] given in [4] subject to constraints.

Minimise: $\sigma_{\ddot{z}_{k}}\left(m_{k}, m_{a}, c_{p}, c_{v}, k_{v}\right)=\left\{\pi R V\left[\frac{c_{p} k_{v}}{2 m_{a}^{3 / 2} c_{v}{ }^{1 / 2}}+\frac{\left(m_{k}+m_{a}\right) c_{v}{ }^{2}}{2 k_{v} m_{a}^{2}}\right]\right\}^{1 / 2}$

Subject to: $\left\{\begin{array}{l}\sigma_{F d / G}\left(m_{k}, m_{a}, c_{p}, c_{v}, k_{v}\right) \leq a=0.5 \\ \sigma_{f d}=\left(m_{k}, m_{a}, c_{p}, c_{v}, k_{v}\right) \leq b=0.05 \\ 150 \leq m_{k} \leq 210 \\ 28 \leq m_{a} \leq 35 \\ 190000 \leq c_{p} \leq 200000 \\ 8950 \leq c_{v} \leq 9050 \\ 1580 \leq k_{v} \leq 1861\end{array}\right.$

In this sub-section, the optimization results are derived for a vehicle travelling at the speed of $40 \mathrm{~m} / \mathrm{s}$ on the road with an irregularity coefficient of power spectrum taking the value of $6.5 \times 10^{-6} \mathrm{~m}^{3}$.

Table 2. Optimal design variables based on the SQP and GA

\begin{tabular}{|c|c|c|c|}
\hline Initial values & Original values & SQP method & GA \\
\hline & & {$[1010101010]$} & {$[1010101010]$} \\
\hline $\mathrm{m}_{\mathrm{k}}[\mathrm{kg}]$ & 200 & 200.0 & 199.918612498 \\
\hline $\mathrm{m}_{\mathrm{a}}[\mathrm{kg}]$ & 33 & 32.0 & 32.0422603233 \\
\hline $\mathrm{c}_{\mathrm{p}}[\mathrm{N} / \mathrm{m}]$ & 200000 & 200000.0 & 200305.819254 \\
\hline
\end{tabular}




\begin{tabular}{|c|c|c|c|}
\hline $\mathrm{c}_{\mathrm{v}}[\mathrm{N} / \mathrm{m}]$ & 9000 & 9100.0 & 9099.82776078 \\
\hline $\mathrm{kv}[\mathrm{Ns} / \mathrm{m}]$ & 1600 & 1580.0 & 1591.74739718 \\
\hline$\sigma_{z_{1}}$ & & 1.2673254442031 & 1.26976709377 \\
\hline & & $\begin{array}{l}\text { Optimum found: } \\
\text { 52 iterations }\end{array}$ & $\begin{array}{l}\text { Optimum found: } \\
\text { 51 generations }\end{array}$ \\
\hline
\end{tabular}

\section{Active Suspension Control using Linear Quadratic Gaussian Control}

The object of linear optimal control theory is to specify an input vector $\underline{u}$ which drives a system to a specific target state in such a way that, during the process, a defined quadratic cost function $\boldsymbol{J}$ is minimized. Minimization of the performance criterion yields an optimal feedback law compromising control effort (actuator power) and control quality (ride comfort and road holding ability).

The quadratic cost function in general form is:

$$
\mathrm{J}=\int_{0}^{T}\left(\underline{x}^{T} \mathrm{Q} \underline{x}+\underline{u}^{T} \mathrm{R} \underline{u}\right) \cdot d x
$$

where $\boldsymbol{Q}$ and $\boldsymbol{R}$ are weighting matrices, $\underline{x}$ is state vector and $\underline{u}$ control vector.

The stochastic cost function $\boldsymbol{J}$ can also be expressed in a matrix form, as follows:

$$
\mathrm{J}=\lim _{T \rightarrow \infty} \mathrm{E}\left\{\int_{0}^{T}\left(\underline{x}^{T} \mathrm{Q}_{c} \underline{x}+2 \underline{x}^{T} \mathrm{~N}_{c} \underline{u}+\underline{u}^{T} \mathrm{R}_{c} \underline{u}\right) d t\right\}
$$

With the performance index we are now capable to search for a state feedback by matrix $\boldsymbol{K}_{c}$ that provides a minimum. Actuator force $\underline{u}$ can is structured as a linear combination of $\underline{x}$ by the state feedback matrix $\boldsymbol{K}_{\mathrm{c}}$ (proportional control):

$$
\underline{u}=-\mathrm{K}_{c} \underline{X}
$$

The closed-loop system is now described by:

$$
\underline{\dot{x}}=\left(\mathrm{A}-\mathrm{BK}_{c}\right) \underline{x}+\mathrm{G} \underline{w}
$$

Feedback matrix $\boldsymbol{K}_{c}$ can be calculated with the help of the matrix Riccati equation.

\section{Limited State Feedback Control}

In a real active or semi-active suspension system it will be of interests to examine the performance of the system under the assumption that only velocity signals are available for the feedback. Linear Quadratic Output Feedback (LQOF) will be used to determine the control feedback matrix. Limited state feedback is often used to minimize the number of states to be determined by measurements, but some states are very difficult to measure.

The control structure can be selected through the output equation:

$$
\underline{y}=\mathrm{C} \underline{x}
$$

Input vector $\underline{u}$ is proportionally related to the output vector $\underline{y}$ by the matrix $\boldsymbol{K}_{0}$ : 


$$
\underline{u}=\mathrm{K}_{0} \underline{y}=\mathrm{K}_{0} \mathrm{C} \underline{x}
$$

The combination of feedback law and the vehicle system gives a closed-loop state equation according to:

$$
\underline{\dot{x}}=\left(\mathrm{A}+\mathrm{BK}_{0} \mathrm{C}\right) \underline{x}+\mathrm{G} \underline{w}
$$

Figure 2 shows the output feedback structure of the closed-loop system.

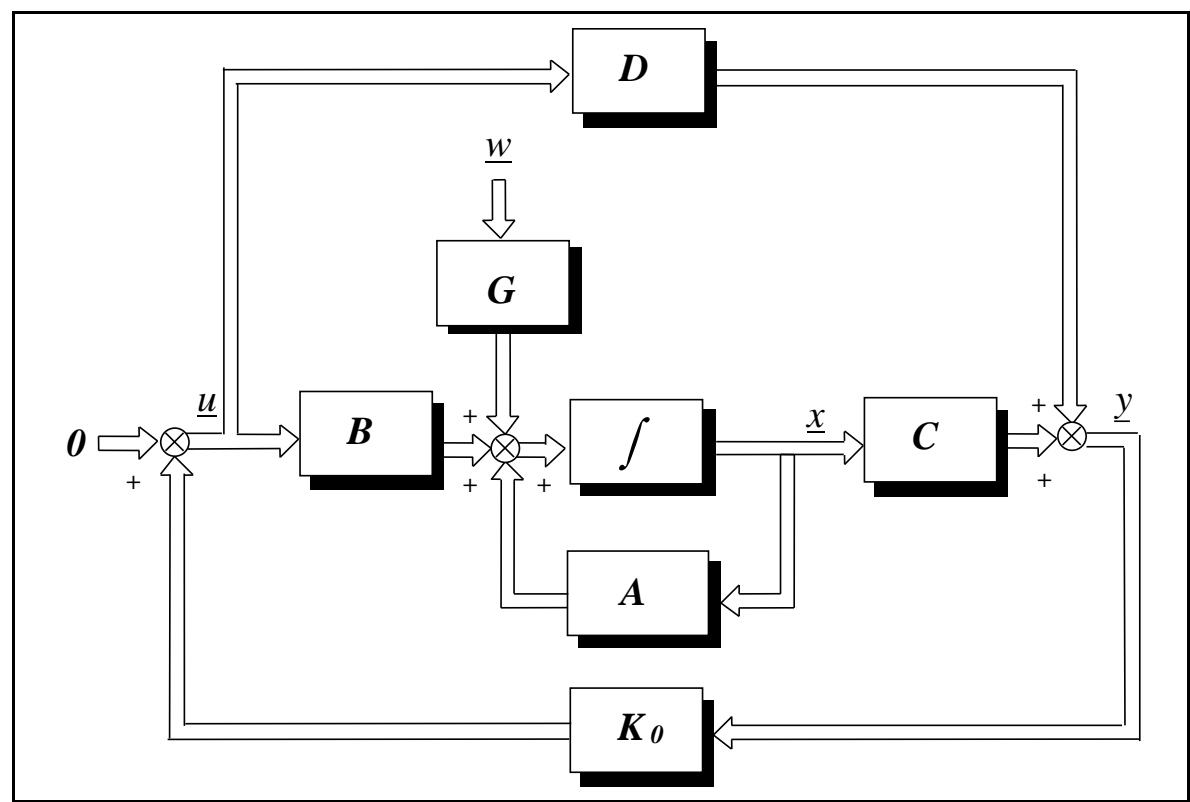

Fig. 2 Output feedback control.

The performance index as defined before remains the same. The design of an optimal constant gain output feedback matrix $\boldsymbol{K}_{0}$ involves the selection of the weighting factors the choice of an initial feedback law and the selection of an initial condition. $\boldsymbol{K}_{0}$ can be found as follows:

$$
\mathrm{K}_{0}=-\mathrm{R}_{c}^{-1}\left(\mathrm{~N}_{c}^{T}+\mathrm{B}^{T} \mathrm{P}\right) \mathrm{SC}^{T}\left(\mathrm{CSC}^{T}\right)^{-1}
$$

where $\boldsymbol{P}=\boldsymbol{P}^{\mathrm{T}} \geq \mathbf{0}$ is the solution of the Lyapunov equation given by:

$$
\mathrm{P}\left(\mathrm{A}+\mathrm{BK}_{0} \mathrm{C}\right)+\left(\mathrm{A}+\mathrm{BK}_{0} \mathrm{C}\right)^{\mathrm{T}} \mathrm{P}+\mathrm{Q}_{\mathrm{C}}+\mathrm{N}_{\mathrm{c}} \mathrm{K}_{0} \mathrm{C}+\mathrm{C}^{\mathrm{T}} \mathrm{K}_{0}^{\mathrm{T}}\left(\mathrm{N}_{\mathrm{c}}^{\mathrm{T}}+\mathrm{R}_{\mathrm{c}} \mathrm{K}_{0} \mathrm{C}\right)=0
$$

where $\boldsymbol{S}=\boldsymbol{S}^{\mathrm{T}} \geq \mathbf{0}$ is the solution of the Lyapunov equation according to:

$$
\mathrm{S}\left(\mathrm{A}+\mathrm{BK}_{0} \mathrm{C}\right)^{\mathrm{T}}+\left(\mathrm{A}+\mathrm{BK}_{0} \mathrm{C}\right) \mathrm{S}+\mathrm{X}=0
$$

For a stochastic case $\boldsymbol{X}$ symbolizes the road noise intensity matrix:

$$
\mathrm{X}=\mathrm{G} \cdot \mathrm{C}_{\underline{w w}} \cdot \mathrm{G}^{\mathrm{T}}
$$

where $\mathrm{C}_{\underline{w w}}$ being the white noise intensity matrix:

The performance criterion can be expressed as:

$$
\mathrm{J}=\operatorname{tr}[\mathrm{P} \cdot \mathrm{X}]
$$

The solution $\boldsymbol{K}_{\boldsymbol{0}}$ must be found using an iterative algorithm using a gradient search technique. 


\section{Simulation Results}

The design of Quadratic Gaussian Controller has been carried out for the quarter car vehicle model, based on the given parameters in tables 3 and 4 . While simulation are performed for passive and active vehicle suspension.

Table 3. Quarter car model parameters

\begin{tabular}{|l||}
\hline$m_{a}=33 \mathrm{~kg}$ \\
\hline$m_{k}=200 \mathrm{~kg}$ \\
\hline$c_{v}=9000 \mathrm{~N} / \mathrm{m}$ \\
\hline$c_{p}=200000 \mathrm{~N} / \mathrm{m}$ \\
\hline$k_{v}=1600 \mathrm{Ns} / \mathrm{m}$ \\
\hline$\omega_{1}=6 \mathrm{~Hz}$ \\
\hline$\omega_{2}=60000 \mathrm{~Hz}$ \\
\hline
\end{tabular}

Table 4. Weighted factors

\begin{tabular}{||c|c|c||}
\hline \hline $\bar{q}_{1}$ & $\bar{q}_{2}$ & $\bar{q}_{3}$ \\
\hline 1.0 & 1.0 & 1.0 \\
\hline $10 \mathrm{E}+10$ & 1.0 & 1.0 \\
\hline 1.0 & $10 \mathrm{E}+10$ & 1.0 \\
\hline 1.0 & 1.0 & $10 \mathrm{E}+10$ \\
\hline
\end{tabular}

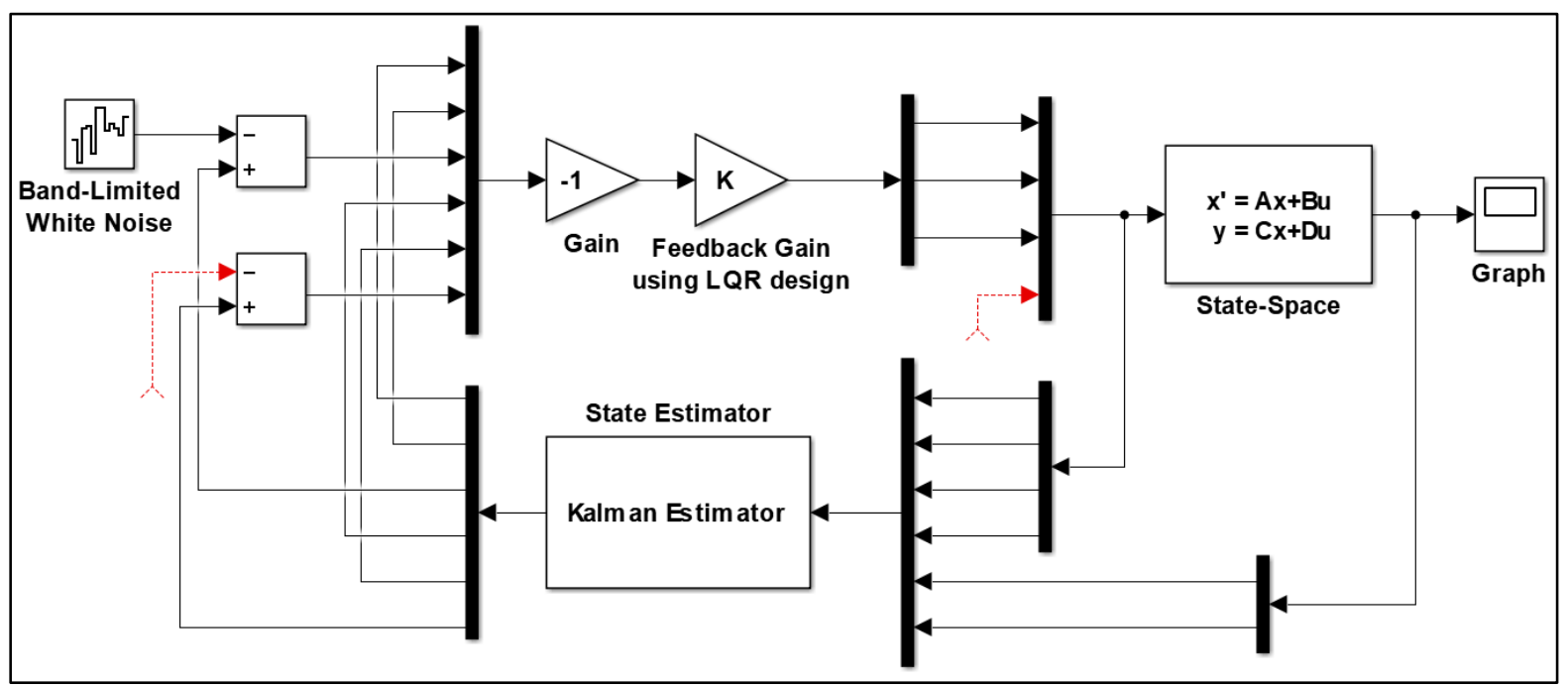

Fig. 3 Simulink model for quarter car

\section{CONCLUSIONS}

A comparative study of two optimization algorithms (genetic algorithms, GAs and sequential quadratic programming, SQP), has been conducted through minimizing the vertical sprung mass acceleration subjected to a suspension working space and dynamic tire load. Active suspension systems using LGC can reduce vertical displacement, as shown in Fig. 5.

The theory of Linear Optimal Control may be applied both for full state feedback and for limited state feedback.

These analysis has shown that despite the presence of an active force generator, according to the information about state variables which may generate the control force in any shape and 
mark in order to ensure the better performance, however the conflict between the ride comfort and road holding still remains.

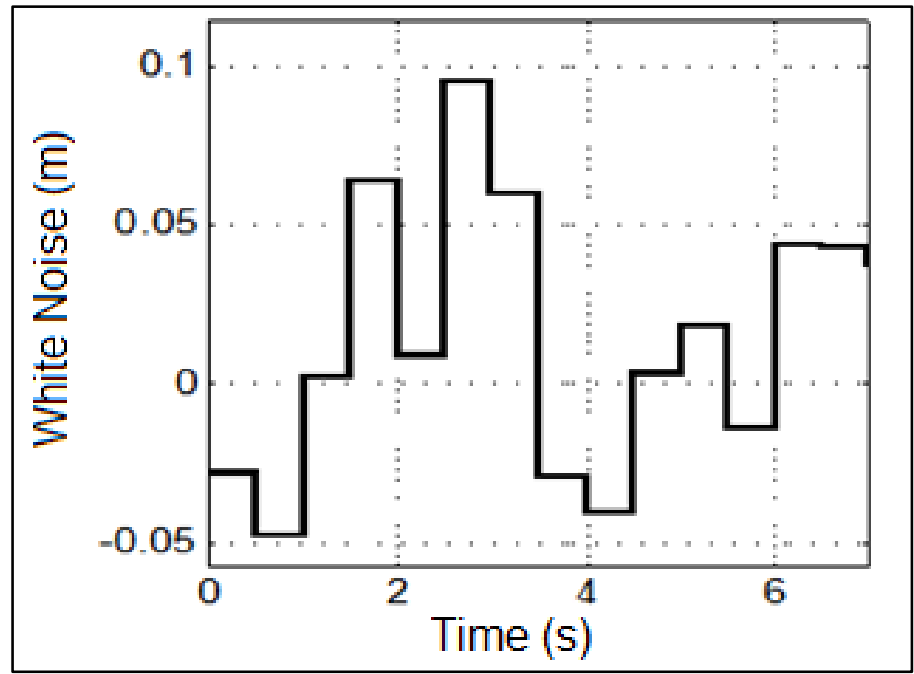

Fig. 4 White noise [m]

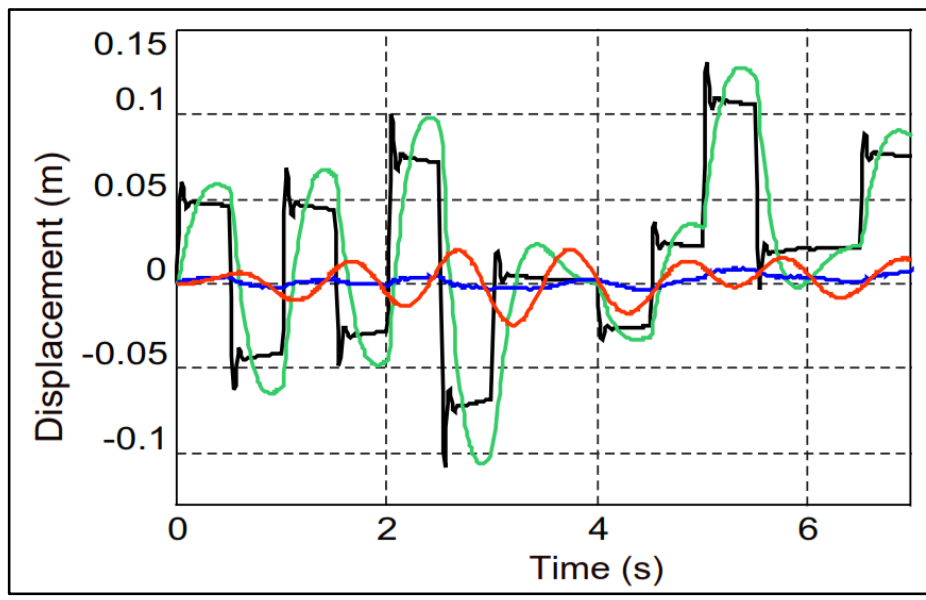

Fig. 5 Displacement in (m) of sprung and unsprung mass for $q_{1}=1, q_{2}=1$ and $q_{3}=1$.

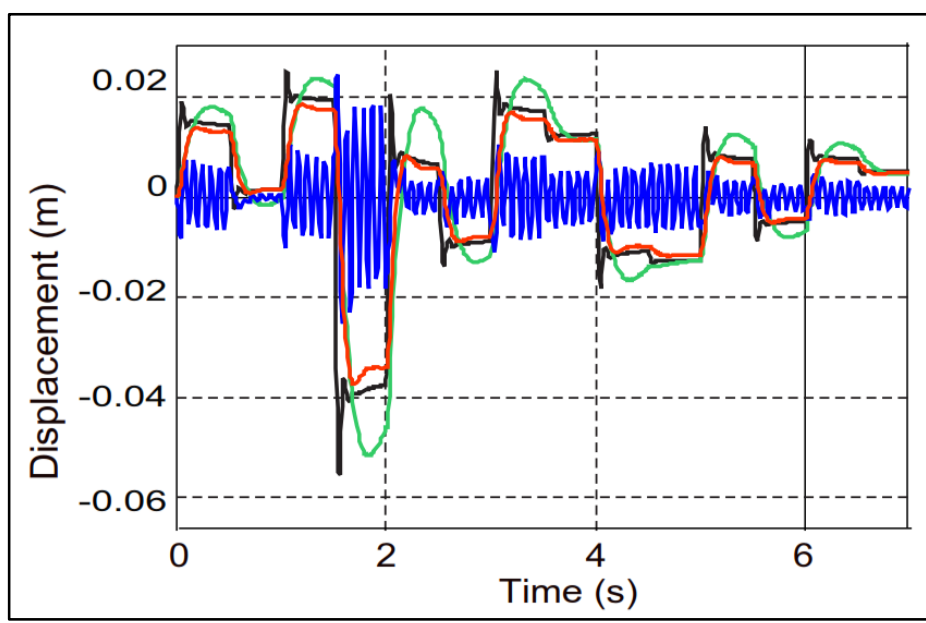

Fig. 6 Displacement in (m) of sprung and unsprung mass for $q_{1}=1, q_{2}=1$ and $q_{3}=10 \mathrm{E}+10$.

For control system design of suspension it is important to specify an input control vector $\underline{u}$. This force drives a system to a specified target state in such a way that during the process, a defined goal function $J$ is minimized. During the determination of a goal function it is 
particularly important the selection of weighting matrices $Q$ and $R$ for different values of weighting factors.

From the simulation in which models are constructed in Simulink, for the quarter car vehicle model, both for active and passive systems, while these systems are simulated by the white noise, it is concluded that:

From the simulations made for the quarter car, the deflection of sprung mass at the active suspension compared with the passive suspension is small especially for the appropriate weighting factors $q_{1}=q_{2}=q_{3}=1$.

Also the same is true for the case when it has been made the compared of speed of the sprung masses of both active and passive systems.

\section{REFERENCES}

[1] R. Likaj. Fuzzy Logic Control of Nonlinear Vehicle Suspension System, PHD thesis, Prishtina, Kosovo, 2005.

[2] R. Likaj. Active Suspension Design Using Linear optimal Control, Master thesis, Prishtina, Kosovo, 1998

[3] R. Likaj, A.Shala, M. Bruqi, M. Qelaj. Optimal Design of Quarter Car Vehicle Suspension System, Trends in the Development of Machinery and Associated Technology - ISSN 1840-4944, Livorno, Italy. 2009, 417 - 420.

[4] R. Likaj, A. Shala, M. Bruqi, Xh. Bajrami. Optimal Design and analysis of Quarter Vehicle Suspension System by using Matlab", 27 DAAAM International Symposium on Intelligent Manufacturing and Automation, Vienna, Austria, 2016.

[5] G. Hoxha, A. Shala, R. Likaj. Pedestrian Crash Model for Vehicle Speed Calculation at Road Accident. International Journal of Civil Engineering and Technology 2017 (8), No. 9, $1093-1099$.

[6] K. Frydrýšek, R. Jančo. Simple Planar Truss (Linear, Nonlinear and Stochastic Approach). Journal of Mechanical Engineering - Strojnícky časopis 2016 (66), No. 2, 5 $-12$.

[7] R. Gogola, J. Murín, J. Hrabovský. Numerical Calculation of Overhead Power Lines Dynamics. Journal of Mechanical Engineering - Strojnícky časopis 2016 (66), No. 2, 13 -22 .

[8] R. Jančo, L. Écsi, P. Élesztős. Fsw numerical simulation of aluminum plates by sysweld - PART I. Journal of Mechanical Engineering - Strojnícky časopis 2016 (66), No. 1, 47 -52 .

[9] A. Shala, M. Bruqi. Trajectory Tracking of Mobile Robot using Designed Optimal Controller. International Journal of Mechanical Engineering and Technology 2017 (8), No. 8, $649-658$.

[10] G. Hoxha, A. Shala, R. Likaj. Vehicle Speed Determination in Case of Road Accident by Software Method and Comparing of Results with the Mathematical Model. Journal of Mechanical Engineering - Strojnícky časopis 2017 (67), No. 2, 51 - 60.

[11] J. Danko, T. Milesich, J. Bucha. Nonlinear Model of the Passenger Car Seat Suspension System. Journal of Mechanical Engineering - Strojnícky časopis 2017 (67), No. 1, 23 28. 